\title{
MS15-P08 | THE MICROSCOPIC ORIGIN OF AXIAL NEGATIVE THERMAL EXPANSION AND NEGATIVE LINEAR COMPRESSIBILITY IN ALPHA- AND BETA-PBALBO 4
}

Gogolin, Mathias (University of Bremen, Institute of Inorganic Chemistry and Crystallography, Bremen, GER); Murshed, M. Mangir (University of Bremen, Institute of Inorganic Chemistry and Crystallography, Bremen, GER); Ende, Martin (University of Vienna, Department of Mineralogy and Crystallography, Vienna, AUT); Kremlicka, Thomas (University of Vienna, Department of Mineralogy and Crystallography, Vienna, AUT); Miletich, Ronald (University of Vienna, Department of Mineralogy and Crystallography, Vienna, AUT); Gesing, Thorsten M. (University of Bremen, Institute of Inorganic Chemistry and Crystallography, Bremen, GER)

$\mathrm{PbMBO}_{4}$-materials ( $\mathrm{M}=\mathrm{Ga}, \mathrm{Al}, \mathrm{Fe}, \mathrm{Mn}, \mathrm{Cr}$ ) have attracted scientific attention due to their magnetic properties [1] as well as their temperature [2]- and pressure-dependent [3] behaviors. The compounds crystallize in space group Pnam and belong to the mullite-type family of compounds, featuring a trans-type chain of edge sharing octahedral $\mathrm{MO}_{6}$-units extending along the $c$-axis. The chains are interconnected in the $a b$-plane by trigonal planar $\mathrm{BO}_{3}$ - and pyramidal $\mathrm{PbO}_{4}$-units. At $\sim 1048 \mathrm{~K}$, the aluminum phase undergoes an irreversible, reconstructive phase transition into the $\beta$ - $\mathrm{PbAlBO}_{4}$-polymorph [4] (space group $\mathrm{Pbcn}$ ). In-situ X-ray diffraction between $13 \mathrm{~K}$ and $1000 \mathrm{~K}$ show both polymorphs to be stable in this temperature range. Using temperature- and pressure-dependent X-ray diffraction and ab-initio modeling, we investigated the axial negative thermal expansion (ANTE) and negative linear compressibility (NLC) in $\alpha$ - and $\beta-\mathrm{PbAlBO}_{4}$ based on single crystal data. The interplay between the Grüneisen functions and the mechanical properties of the systems determine the ANTE. The structural features suggest that the NLC arises from the topology of the polymorphs, which is directed by the stereochemical active lone electron pairs of the $\mathrm{Pb}^{+2}$ cations.

[1] A.I. Pankrats, et al., Solid State Phenom. 215 (2014) 372-377.

[2] T.M. Gesing, et al., Zeitschrift Für Krist. - New Cryst. Struct. 227 (2012) 285-286.

[3] P. Kalita, Dissertation, University of Nevada, Las Vegas, 2015.

[4] H. Park, J. Barbier, R.P. Hammond, Solid State Sci. 5 (2003) 565-571. 